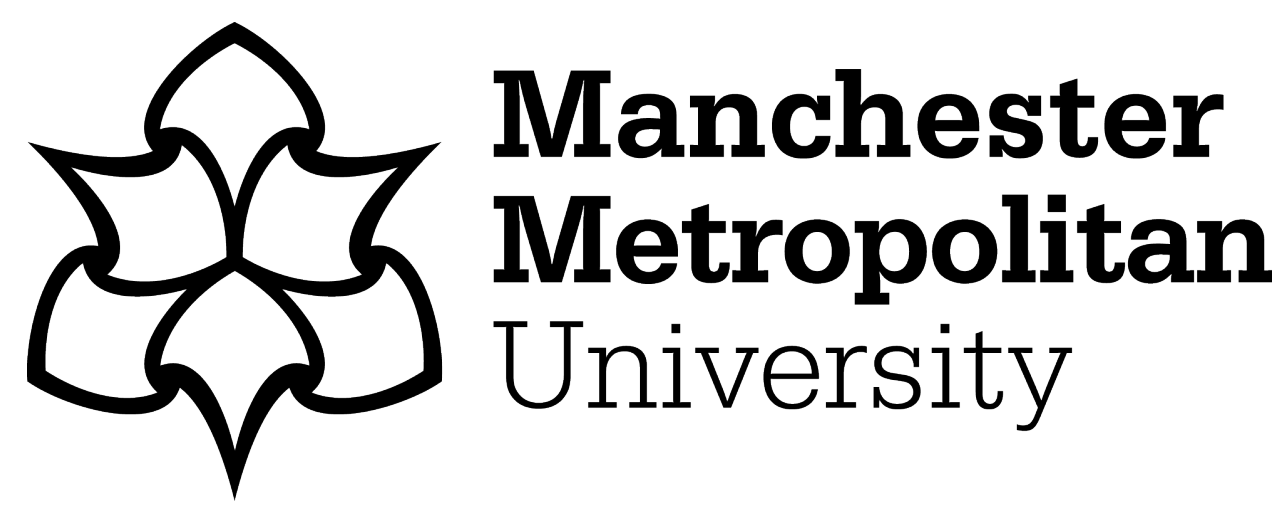

Dos'Santos, T, Thomas, C, Comfort, P, McMahon, JJ, Jones, PA, Oakley, NP and Young, $A L$ (2018) Between-session reliability of isometric midthigh pull kinetics and maximal power clean performance in male youth soccer players. Journal of Strength and Conditioning Research, 32 (12). pp. 3364-3372. ISSN 1064-8011

Downloaded from: https://e-space.mmu.ac.uk/626022/ Version: Accepted Version

Publisher: National Strength and Conditioning Association

DOI: https://doi.org/10.1519/JSC.0000000000001830

Please cite the published version 


\section{BETWEEN-SESSION RELIABILITY OF ISOMETRIC MID-THIGH PULL KINETICS AND MAXIMAL POWER CLEAN PERFORMANCE IN MALE YOUTH SOCCER PLAYERS}

Original Research

Funding Statement: No external funding was received for this work.

Conflict of Interest: There are no conflicts of interest concerning this paper

Thomas Dos'Santos ${ }^{1 \#}$, Christopher Thomas ${ }^{1}$, Paul Comfort ${ }^{1}$, John J McMahon ${ }^{1}$, Paul A Jones $^{1}$, Nick P Oakley ${ }^{1,2} \&$ Ashley L Young ${ }^{1,2}$

${ }^{1}$ Human Performance Laboratory, Directorate of Sport, Exercise, and Physiotherapy, University of Salford, Greater Manchester, United Kingdom

${ }^{2}$ Crewe Alexandra Football Club, Crewe, United Kingdom

${ }^{\#}$ Corresponding Author: Thomas Dos'Santos

Telephone: +447961744517

Email: t.dossantos@edu.salford.ac.uk

Preferred running head: Reliability of isometric kinetics and power clean

Abstract word count: 261 words

Manuscript word count: 4653 words

Number of tables and figures: 3 Tables 
BETWEEN-SESSION RELIABILITY OF ISOMETRIC MID-THIGH PULL KINETICS AND MAXIMAL POWER CLEAN PERFORMANCE IN MALE YOUTH SOCCER PLAYERS 


\section{ABSTRACT}

The aim of the study was to determine the between-session reliability of isometric mid-thigh pull (IMTP) kinetics and maximal weight lifted during the power clean (PC) in male youth soccer players, and to identify the smallest detectable differences between sessions. Thirteen male youth soccer players (age: $16.7 \pm 0.5$ years, height: $1.80 \pm 0.08 \mathrm{~m}$, mass: $70.5 \pm 9.4 \mathrm{~kg}$ ) performed three IMTP trials, while only ten soccer players performed maximal power cleans. These were performed twice, separated by 48 hours to examine the between-session reliability. Intraclass correlation coefficients (ICC) and coefficient of variation (CV) demonstrated high levels of within-session $(\mathrm{ICC}=0.84-0.98, \mathrm{CV}=4.05-10.00 \%)$ and between-session reliability (ICC $=0.86-0.96, \mathrm{CV}=3.76-7.87 \%$ ) for IMTP kinetics (peak force and time-specific force values 30-250 ms) and maximal PC (ICC $=0.96, \mathrm{CV}=3.23 \%$, all meeting minimum acceptable reliability criteria. No significant differences $(p>0.05$, effect size $\leq 0.22$ ) were revealed between sessions for IMTP kinetics and maximal PC performance. Strength and conditioning coaches and practitioners should consider changes of $>6.04 \%$ in maximal PC and changes in IMTP kinetics of $>14.31 \%$ in force at $30 \mathrm{~ms},>14.73 \%$ in force at $50 \mathrm{~ms},>12.36 \%$ in force at $90 \mathrm{~ms},>12.37 \%$ in force at $100 \mathrm{~ms},>14.51 \%$ in force at 150 $\mathrm{ms},>11.71 \%$ in force at $200 \mathrm{~ms},>7.23 \%$ in force at $250 \mathrm{~ms}$ and $>8.50 \%$ in absolute peak force as meaningful improvements in male youth soccer players. Decrements in the IMTP kinetics greater than aforementioned values could possibly be used as an indicator of neuromuscular fatigue and preparedness for training or competition.

KEY WORDS time-specific force, peak force, smallest detectable difference, assessment, force-time curve 


\section{INTRODUCTION}

Strength and power are considered key determinants of dynamic athletic performance in particular sporting tasks which require high force generation in short time intervals (30). Weightlifting movements and their derivatives are considered to be an effective training modality for enhancement of power and subsequent transfer to dynamic performance (34). Development of power based on Olympic lifts and their derivatives are usually prescribed on percentages of a one repetition maximum (1RM) power clean (PC) (34) to develop individualised training programs, while the $1 \mathrm{RM}$ PC is also commonly used to assess and monitor the effectiveness of training interventions $(6,11)$.

The neuromuscular qualities of the lower limb can also be evaluated using force-time curves (FTC) recorded from the isometric mid-thigh pull (IMTP). The IMTP is modelled on the second pull position of the clean whereby the largest forces and velocities are generated (14, 19). The use of IMTP assessments are becoming more accessible in research and testing batteries of applied practice due to the accessibility of cheaper force platforms and the development of portable IMTP racks. The IMTP induces minimal fatigue, and is time efficient and potentially safer than performing dynamic $1 \mathrm{RM}$ testing $(5,7)$, with strong correlations observed between IMTP peak force (PF) and 1RM back squat $(r \geq 0.96)(28,29)$, $1 \mathrm{RM}$ snatch and clean and jerk $(r \geq 0.83)$ (4) and $1 \mathrm{RM}$ deadlift $(r=0.88)$ (7). Peak force is commonly analysed during the IMTP but a further advantage is the ability to inspect an athlete's ability to produce force at specific time intervals $(4,8,18)$, rate of force development $(\operatorname{RFD})(4,8,18)$ and impulse $(5,36)$. Monitoring of these kinetic variables can subsequently allow practitioners to create force-time strength profiles for their athletes. Not only can the acute neuromuscular qualities of an athlete be assessed via the IMTP to identify strengths and weaknesses and inform training prescription, but can also be used to measure the acute and longitudinal effectiveness of training interventions (3). Furthermore, the IMTP 
can also be used for talent identification and establishing normative data in a range of athlete populations, can also be used to assess the neuromuscular preparedness over consecutive days (15) while more recently dynamic strength indexes (37) and muscle strength asymmetries (10) have also been established via IMTP assessments.

Of importance to sporting success and dynamic tasks is an athlete's ability to produce high forces in short time intervals $(9,30,42)$. As previously stated, a unique advantage of the IMTP is RFD at pre-determined time bands, time-specific force values and impulse at predetermined time bands can be derived from the FTC and can be subsequently monitored (4, $5,8,18,36)$. These variables have demonstrated high within-session reliability $(4,5,8,18$, 36) and have also demonstrated significant relationships with a range of athletic tasks $(26,36$, 41). For example, West et al. (41) reported a significant inverse relationship between IMTP force at $100 \mathrm{~ms}$ and $10 \mathrm{~m}$ sprint time $(\mathrm{r}=-0.54)$, and when expressed relative to body mass it was significantly associated with $10 \mathrm{~m}$ sprint and countermovement jump height $(\mathrm{r}=-0.68$ and 0.43 ) in professional rugby players. Leary et al. (26) reported moderate relationships between IMTP force at $150 \mathrm{~ms}$ with average and maximal club head speed $(\mathrm{r}=0.46-0.47)$ in golfers. Furthermore, Thomas et al. (36) found strong significant inverse relationships between impulse 100 and $300 \mathrm{~ms}$ with $5 \mathrm{~m}, 20 \mathrm{~m}$ and modified 505 change of direction performance ( $r=-0.58$ to -0.78$)$ in collegiate male athletes. Consequently the abovementioned studies highlight the importance of evaluating the time-specific force, RFD and impulse contractile properties of athletes.

For a test to be deemed applicable for use in research and strength and conditioning settings, the test must produce high levels of reliability and reproducibility so meaningful changes in performance can be determined (27). Additionally, strength and conditioning coaches should also be aware of familiarisation and learning effects of the test, so that sound conclusions about whether changes seen in response to a training intervention are meaningful or not can 
be made (27). Although high levels of within-session reliability have been observed for timespecific force values, RFD and impulse at pre-determined time bands $(4,5,8,18,36)$ there is a lack of research demonstrating the between-session reliability of these variables. The between-session reliability of PF has been confirmed to be highly reliable (ICC $\geq 0.89)(5,7$, 37) although to our knowledge only one study has evaluated the between-session reliability of time-specific force values (7). De Witt et al. (7) found force at $250 \mathrm{~ms}$ be highly reproducible between sessions in astronauts $(\mathrm{ICC}=0.80$ ), however the other time specific force values (30-200 ms) failed to meet acceptable reliability criteria. Unfortunately the authors failed to present the specific ICCs for the variables that did not meet acceptable reliability criteria. It is postulated that time-specific force values may demonstrate greater variability and be more sensitive to change between sessions however further research is required to support this notion. Research from Comfort et al. (5) conducted the most comprehensive analysis of the between-session reliability of PF, maximum RFD and impulse 100, 200 and $300 \mathrm{~ms}$ demonstrating high levels of reliability for all kinetic variables (ICC > 0.819). Furthermore to our knowledge Comfort et al. (5) is the first study to provide standard error of measurement (SEM) and smallest detectable differences (SDD) for kinetic variables during the IMTP. Standard errors of measurement indicate the range in which an individual's true score is likely to lie (38), whereas SDD allow practitioners to decide whether a change in an individual's performance is statistically significant (25).

Although numerous studies have considered the within-session reliability of IMTP kinetics $(4,8,10,18)$, limited research exists investigating the between-session reliability of IMTP kinetics (5); in particular time-specific force values are of importance given the relationship with dynamic tasks $(24,26,41)$ and specificity to ground contact times of various tasks $(9$, 42). In light of this, it is difficult for strength and conditioning coaches and practitioners to determine what magnitude of change in IMTP kinetics is deemed meaningful. There is a need 
therefore to determine what a meaningful change in IMTP kinetics to permit the strength and conditioning coach and athlete to determine if any change in performance is greater than the variation between training sessions.

As one of the main benefits of IMTP testing is the acute and longitudinal monitoring of neuromuscular performance to determine the effectiveness of training interventions, it is somewhat surprising that only one study has provided SDD values for kinetic variables (5). Without providing measurement error values, it is unknown if changes in performance are attributed to interventions or measurement error. Although it should be noted the cohort of the abovementioned study were all male multisport collegiate athletes and therefore the SEM and SDD values are likely to be based on experience and familiarity with the postures and expression of force in this position. Various athletic populations from different sports have been assessed in terms of IMTP kinetics including multisport collegiate athletes (5), professional rugby league players $(10,41)$, golfers (26), female volleyball players (18), sprints cyclists (33) and weightlifters (4). Conversely, there is a lack of research providing reliability and normative IMTP kinetics or PC data in an all-male soccer population. The aim of the study, therefore, was to determine between-session reliability of IMTP kinetics and 1RM power clean, in male youth soccer athletes, and to identify the SDD between sessions. It was hypothesized that all IMTP kinetics and 1RM PC would be highly reproducible between testing sessions with no significant differences between testing sessions.

\section{METHODS}

Experimental approach to the problem 
This study used a within-subject repeated-measures research design, whereby 1RM PC and three IMTP trials were each performed on two separate testing sessions, 48 hours apart. Intraclass correlation coefficients, coefficient of variation and typical error of measurement were used to determine reliability between trials, with paired samples' $t$ tests to determine whether there were any significant differences between testing sessions, for PC and IMTP kinetic variables. Subjects were asked to replicate their fluid and food intake 24 hours before each day of testing, to avoid strenuous exercise for 48 hours before testing. All testing was performed at the same time of day to minimize the effect of circadian rhythms.

\section{$\underline{\text { Subjects }}$}

Professional youth soccer players $(n=13$, age: $16.7 \pm 0.5$ years, height: $1.80 \pm 0.08 \mathrm{~m}$, mass: $70.5 \pm 9.4 \mathrm{~kg}$ ) participated in this study. The investigation was approved by the institutional ethics review board, and all subjects were informed of the benefits and risks of the investigation prior to signing an institutionally approved consent and parental assent documents to participate in the study. The study conformed to the principles of the World Medical Association's Declaration of Helsinki. Subjects were familiar with the IMTP protocol and had 6-12 months resistance training experience of the PC and its' derivatives; all IMTP trials and 1RM PCs were assessed by certified strength and conditioning specialists. At the time of testing subjects were in the final week of their 7 week preseason mesocycle.

\section{$\underline{\text { Procedures }}$}

All subjects performed a standardized warm up comprised of five minutes of dynamic stretching before advancing to dynamic mid-thigh clean pulls. One set of five repetitions was performed with an empty barbell (Werksan Olympic Bar, Werksan, Moorsetown, NJ, USA) 
followed by two isometric efforts at a perceived intensity of 50 and $75 \%$ of maximum effort, interspersed with a one-minute recovery.

\section{$\underline{\text { Isometric mid-thigh pull protocol }}$}

The IMTP testing was performed on a portable force plate sampling at $1000 \mathrm{~Hz}$ (Kistler, Switzerland, Model 9286AA, SN 1209740) using a portable IMTP rack (Fitness Technology, Adelaide, Australia. Sampling at $1000 \mathrm{~Hz}$ has been shown to produce high reliability for isometric force-time variables (8). A cold rolled steel bar was positioned to correspond to the athlete's second-pull power clean position just below the crease of the hip (4). The bar height could be adjusted ( $3 \mathrm{~cm}$ increments) at various heights above the force plate to accommodate different sized athletes. Athletes were strapped to the bar in accordance to previous research (16) and positioned in their self-selected mid-thigh clean position (knee joint angle of 137$146^{\circ}$ a and a hip angle of $140-149^{\circ}$ ) established in the familiarization trials whereby feet were shoulder width apart, knees were flexed over the toes, shoulders were just behind the bar, and torso was upright $(8,10)$. Researchers have demonstrated that differences in knee and hip joint angles during the IMTP do not influence kinetic variables, justifying the selfselected preferred mid-thigh position (5). Beckham et al. (23) has shown notable differences in PF between mid-thigh pull and preferred lockout position during isometric deadlifts, as such it was ensured that all self-preferred IMTP trials performed in present study resembled the position of second pull of the clean and not a lockout position. The specific joint angles were replicated for each subject both within and between session, to ensure that any observed differences were not as a result of changes in posture. All subjects received standardized instructions to pull as fast and as hard as possible and push their feet into the force plate until being told to stop, as these instructions have been shown to be optimal results (16). Once the body was stabilised (verified by watching the subject and force trace) the IMTP was initiated with the countdown " $3,2,1$ pull," with subjects ensuring that maximal effort was applied for 
five seconds. Ground reaction force data were collected for a duration of eight seconds from the portable force platform which was interfaced with a laptop and recorded using Bioware software (Version 5.11; Kistler Instrument Corporation, Switzerland). Minimal pre-tension was allowed to ensure there is no slack in the body prior to initiation of pull and subjects were instructed to be as still as possible during the weighing period, without initiating a pull on the bar, until given the instructions to 'pull'. Verbal encouragement was given for all trials and subjects. Trials that did not have a stable baseline force trace were rejected along with trials with visible countermovements, subsequently another trial was performed. Subjects performed a total of three maximal effort trials and interspersed with 2-minute rest periods.

\section{$\underline{\text { Isometric force-time curve assessment }}$}

All force-time data recorded during the IMTP were inspected using a customized analysis spreadsheet to determine specific force-time characteristics. The maximum force generated during the five second maximum effort IMTP was reported as the absolute PF. Additionally, time-specific force values at $30 \mathrm{~ms}\left(\right.$ Force $\left._{30}\right), 50 \mathrm{~ms}\left(\right.$ Force $\left._{50}\right), 90 \mathrm{~ms}$ (Force 90$), 100 \mathrm{~ms}$ (Force 100$), 150 \mathrm{~ms}$ (Force 150$), 200 \mathrm{~ms}$ (Force 200$)$ and $250 \mathrm{~ms}$ (Force 250$)$ were calculated. The onset of the pull was determined when vertical ground-reaction force deviated $40 \mathrm{~N}$ from the average BW during the weighing period. This $40 \mathrm{~N}$ onset threshold has been used previously demonstrating high reliability (10) and was high enough to overcome the noise associated during the weighing period and preserved as much of the signal as possible, preventing early triggering of the analysis of the force-time data. The combined residual force and BW were calculated as the average force over a 1 second stationary weighing period (in mid-thigh pull position posture) prior to the initiation of the IMTP. 


\section{$\underline{\text { Power clean }}$}

1RM PCs were performed after the IMTPs. Participants warmed up by performing the exercises with submaximal loads that they were accustomed to from their normal training, after the National Strength and Conditioning Association (NSCA) protocol (20). Participants were permitted a maximum of six progressively increasing loads, although all participants completed the testing within four to five attempts. If athletes caught the bar below a $90^{\circ}$ knee angle, this was classed as a no lift and the lift was performed again after a 3-minute rest period. Subjects adopted their normal foot and hand placement during the $\mathrm{PC}$, which was standardized between sessions. Verbal encouragement was provided throughout maximal testing, with the technical feedback regarding the depth of the catch for the power clean. Participants were not informed of the loads lifted until the end of the second testing session. All testing was performed using standardized barbells (Werksan weights and Olympic bar; Werksan, Moorestown, New Jersey, USA) and lifting platforms.

\section{$\underline{\text { Statistical analyses }}$}

Statistical analyses were performed using SPSS software version 22 (SPSS, Chicago, Ill, USA) and a custom reliability spreadsheet (21). Normality for all variables was confirmed using a Shapiro Wilks-test. Within-session reliability and between-session reliability were assessed via intra class coefficients (ICC), 95\% confidence intervals (CI), coefficient of variation $(\mathrm{CV})$ and typical error of the measurement (TE) expressed in relation to the $\mathrm{CV}$ in absolute units. The CV was calculated based on the mean square error term of logarithmically transformed data (21). The SEM was calculated using the formula: $S D($ pooled $) * \sqrt{(1-\text { ICC })}$ (38), whereas the SDD was calculated from the formula: $(1.96$ * $(\sqrt{(2)}) * \operatorname{SEM}(6,25)$. Minimum acceptable reliability was determined with an ICC $>0.7$ and 
$\mathrm{CV}<15 \%(2,18)$. Paired sampled $\mathrm{t}$ tests were used to compare 1RM PC and IMTP kinetics between sessions. Standardized differences effect sizes (ES) were calculated using Cohen's $d$ $=$ Mean session $1-$ Mean session $2 / \mathrm{SD}$ (pooled) and interpreted using the scale presented by Hopkins et al. (22). Post hoc statistical power was calculated using G*Power (Version 3.1,University of Dusseldorf, Germany) (12). The significance was set at $\mathrm{p} \leq 0.05$.

\section{RESULTS}

High within-session reliability was observed for all IMTP kinetics $(\mathrm{ICC}=0.84-0.98, \mathrm{CV}=$ 4.05-10.00\%), all achieving minimum acceptable reliability criteria (Table 1). Additionally, high between-session reliability was observed for all IMTP kinetics $(\mathrm{ICC}=0.86-0.96, \mathrm{CV}=$ 3.76-7.87\%), all achieving minimum acceptable reliability criteria (Table 2). No significant differences were observed for all IMTP kinetics between testing sessions ( $p>0.05, \mathrm{ES} \leq 0.22$ ) with effect sizes showing trivial to small differences in IMTP kinetics (Table 2). IMTP descriptive statistics, ICC, CV and TE are presented in Tables $1 \& 2$ for within- and betweensessions; SEM and SDD are also presented in Table 2. SDD for IMTP kinetics of $14.31 \%$, $14.73 \%, 12.36 \%, 12.37 \%, 14.51 \%, 11.71 \%, 7.23 \%$ and $8.50 \%$, were attained for force 30 , force $_{50}$, force 90, force $_{100}$, force $_{150}$, force 200 , force 250 and PF, respectively (Table 2).

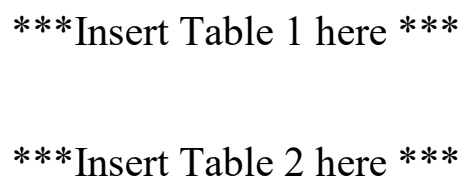

High between-session reliability was observed for 1RM PC performance $(\mathrm{ICC}=0.96, \mathrm{CV}=$ $3.23 \%$ ) achieving minimum acceptable reliability criteria (Table 3). No significant differences $(p=0.78, E S=0.04)$ were revealed between testing sessions in 1RM PC. 1RM PC 
between-session descriptive statistics, ICC, CV, TE, SEM and SDD are presented in Table 3. SDD for 1RM PC performance was $3.77 \mathrm{~kg}(6.04 \%)$.

***Insert Table 3 here ** 


\section{DISCUSSION}

The aim of this study was to determine between-session reliability of IMTP kinetics and 1RM PC, in male youth soccer athletes, and to identify the SDD between sessions to determine meaningful changes in performance. The results from this study demonstrated high betweensession reliability for IMTP kinetics and 1RM PC in youth male soccer players, all achieving minimum acceptable reliability criteria (Tables $2 \& 3$ ). Furthermore, no significant differences $(p>0.05)$ were observed in IMTP kinetics and 1RM PC between testing sessions suggesting there was no learning effect in this population (Tables $2 \& 3$ ). Consequently, these results show that that the IMTP and PC are highly reliable assessments to assess the strength and power characteristics of youth male soccer athletes. Practitioners should therefore be confident in assessing isometric force-time characteristics of their athletes and confident in monitoring the response of training interventions via the IMTP and PC due to the low measurement errors observed in this study (Tables 1-3).

Comfort et al. (5) reported PF, maximum RFD and impulse (100, 200 and $300 \mathrm{~ms}$ ) to demonstrate high between-session reliability in eight collegiate male athletes (ICC >0.819) and to our knowledge was the first study to provide SEM and SDD values for IMTP kinetics. The authors revealed that changes $>1.3 \%$ in $\mathrm{PF},>10.3 \%$ in maximum $\mathrm{RFD},>5.3 \%$ in impulse at $100 \mathrm{~ms},>4.4 \%$ in impulse at $200 \mathrm{~ms}$, and $>7.1 \%$ in impulse at $300 \mathrm{~ms}$ should be considered meaningful. We revealed similar between-session reliability for IMTP PF (Table 2) and found a higher SDD value for IMTP PF in youth male soccer players $(8.50 \%)$. This difference could be potentially attributed to the higher training age and experience in strength training of the population used by Comfort et al. (5).

In the current study PF demonstrated the high within-session (ICC $=0.97-0.98, \mathrm{CV}=4.05$ $4.26 \%$ ) and between-session reliability ( $\mathrm{ICC}=0.96, \mathrm{CV}=4.61 \%$ ); this is similar to the 
observations of Comfort et al. (5) (ICC = 0.99), De Witt et al. (7) $(\mathrm{ICC}=0.89)$ and Thomas et al. (37) ( $\mathrm{ICC}=0.95, \mathrm{CV}=3.8 \%)$ who also observed PF to demonstrate the highest withinsession and between-session reliability. Similarly, corroborative research from Haff et al. (18) also found PF to demonstrate high-within session reliability $(\mathrm{ICC}=0.99, \mathrm{CV}=1.7 \%)$ in female volleyball players. While additional research in youth male rugby players also demonstrated comparable PF reliability $(\mathrm{ICC}=0.97, \mathrm{CV}=3.2 \%)(8)$. Moreover, similar ICCs have also been observed for PF in surfers (31), weightlifters $(4,16)$ and sprint cyclists (33). Furthermore, no significant differences were observed in PF between sessions $(p=0.78$, $\mathrm{ES}=0.03$ ) were observed in the present study suggesting there no was no learning effect.

The ability to examine the maximum force production capabilities of the lower limbs in athletes is an integral part of strength profiling, identifying athlete's strengths and weaknesses and monitoring the effectiveness of training interventions (27). Strength and conditioning coaches should consider assessing the maximum force capabilities of their athletes via the IMTP due to the high between-session reliability observed in this study and previous work (5, 7). Practitioners who are working with athletes with low resistance training experience and may not want to perform maximal repetition testing with back squat and deadlifts due to the potential risk of injury could use the IMTP as an alternative assessment to assess maximum strength due to the strong relationships with back squat (28) and deadlift 1RM (7) performance. Furthermore, the IMTP is a time efficient process, quicker to administer than maximal dynamic strength testing, induces minimal fatigue and poses a reduced risk of injury $(7,28)$.

High levels of within-session ( $\mathrm{ICC}=0.85-0.94, \mathrm{CV}=5.75-10 \%)$ and between-session reliability ( $\mathrm{ICC}=0.86-0.96, \mathrm{CV}=3.76-7.87 \%$ ) were observed in this study for all time- 
specific force values; all meeting minimum acceptable reliability criteria (Tables $1 \& 2$ ). To our knowledge, De Witt et al. (7) is the only other study to investigate the reproducibility of time-specific force values, reporting force 250 to be the only variable to achieve acceptable reliability criteria $(\mathrm{ICC}=0.80)$ but did not provide $\mathrm{CV}, \mathrm{TE}, \mathrm{SEM}$ or SDD values. These differences in findings could be attributed to the differences in population (astronauts vs soccer), and potentially greater familiarisation of the expression of force via weightlifting derivatives in present study. Conversely, the reliability measures observed in the present study for time-specific force values are comparable to the within-session ICCs of previous research (4, 24); while Dos'Santos et al. (8) recently observed similar within-session reliability $\left(\mathrm{ICC}=0.80-0.90, \mathrm{CV}=7.3-10.1 \%\right.$ ) for force ${ }_{100}$, force ${ }_{150}$ and force 200 in youth rugby league players. Furthermore, Haff et al. (18) reported higher reliability for timespecific force values $(30,50,90,100,150,200$, and $250 \mathrm{~ms}$; ICC $=0.99, \mathrm{CV}=2.3-2.7 \%)$ in female volleyball players, however it should be noted that statistical analysis was conducted on the two best trials which may explain the lower CV.

Although the present study did not inspect RFD or impulse from the IMTP like Comfort et al. (5) this study is the first study to confirm high and acceptable between-session reliability of time-specific force values, providing ICC, CV, TE, SEM and SDD values. Time-specific force values should therefore be considered highly reproducible between sessions male youth soccer players (Table 2). SEMs indicate the range in which an individual's true score is likely to lie (38), whereas SDD allow practitioners decide whether a change in an individual's performance is statistically significant (25). Consequently, strength and conditioning coaches and practitioners should consider changes of IMTP kinetics of $>14.31 \%$ in force $30,>14.73 \%$ in force $_{50},>12.36 \%$ in force $90,>12.37 \%$ in force ${ }_{100},>14.51 \%$ in force $150,>11.71 \%$ in force 200 , $>7.23 \%$ in force 250 and $>8.50 \%$ in $\mathrm{PF}$ as a true improvement in neuromuscular performance 
from a training intervention in male youth soccer players. Decrements in the IMTP kinetics greater than aforementioned values could possibly be used as an indicator of neuromuscular fatigue and preparedness for training or competition (15). This could subsequently allow strength and conditioning coaches to adapt training sessions for fatigued athletes. Specifically, it may be more suitable for strength and conditioning coaches to monitor responses to training interventions and neuromuscular fatigue using kinetic variables $\mathrm{PF}$ and force $_{250}$ due to the highest ICCs and lowest measurement errors were observed with these variables (Table 2).

The ability to generate force in short time intervals is integral and is arguably of greater importance of than maximum force production for many sports and dynamic tasks $(17,30$, $32)$; although should be noted that these are closely related $(4,24,33)$. By assessing timespecific force values from IMTP assessment, strength and conditioning coaches and practitioners are able inspect the force production capabilities of athletes over time intervals similar to the periods of force application of their sports. Consequently, force-time strength profiles can be created to identify strengths and weaknesses in an athlete's rapid force production capabilities. By monitoring only PF practitioners are failing to obtain vital pieces of information regarding the rapid force production contractile properties of their athletes. For example, hypothetically an athlete may not improve their PF production capabilities from a specific training intervention however enhancements in time-specific force values (30-250 ms) show a positive adaptation to the training intervention and arguably may be more crucial to sporting success $(17,30,32)$. If PF was only examined the specific athletes response to the training intervention may have been deemed ineffective. Conversely, insight into an athletes time-specific force value shows a positive response to the training intervention. Therefore, strength and conditioning coaches and practitioners should not only inspect PF, but in 
addition time-specific force values to evaluate the force-time strength profiles $(4,8,18)$ and effectiveness of training interventions.

Researchers have shown seasonal changes in fitness and strength characteristics throughout a season $(1,13)$ and the specific training phase has also been shown to influence jumping performance measurement error (35). Therefore, it should be acknowledged that the results of this study may only be representative of these athletes at the specific time of testing and the reliability and SDD are likely to change throughout the competitive season. However, to our knowledge no literature exists longitudinally monitoring the reliability of IMTP force-time characteristics over a competitive season. Therefore, a future direction of research is to investigate the seasonal variations in IMTP kinetics and reliability of these variables.

The PC is recommended as an exercise for the development of power in soccer players and also been further recommended as part of the strength and power testing battery in this population $(39,40)$. To our knowledge, this study is the first to inspect the between-session reliability of 1RM PC in relatively inexperienced youth male soccer players (6-12 months training age), confirming the $1 \mathrm{RM} P C$ to be highly reliable $(\mathrm{ICC}=0.96, \mathrm{CV}=3.23 \%, \mathrm{SEM}=$ $1.96 \mathrm{~kg}, \mathrm{SDD}=3.77 \mathrm{~kg}, 6.04 \%)$, with no significant differences $(\mathrm{p}=0.78, \mathrm{ES}=0.04)$ between testing sessions (Table 3); in agreement with previous research $(6,11)$. Comfort and McMahon (6) observed similar findings revealing high between-session reliability $(\mathrm{ICC}=0.99)$, no significant differences $(\mathrm{p}>0.05)$ in $1 \mathrm{RM}$ PC between testing sessions and slightly lower SEM (1.45 kg) and SDD values (4.04 kg, 4.46\%) in inexperienced male collegiate athletes. Furthermore, Faigenbaum et al. (11) also revealed high between-session reliability $(\mathrm{ICC}=0.99)$ and no significant differences $(\mathrm{p}>0.05)$ in $1 \mathrm{RM}$ PC between sessions in adolescent male athletes of a similar age to the present study $(15.9 \pm 1.1$ years $)$ but with a 
higher resistance training experience $(16.5 \pm 1.1$ months $)$. The authors reported a slightly higher minimal difference of $8 \mathrm{~kg}$ with a typical error of $2.3 \mathrm{~kg}$ in comparison to the present study (Table 3$)$. The authors showed a mean difference of $0.8 \mathrm{~kg}(1.1 \%)$ between sessions, again comparable to the mean differences of $0.25 \mathrm{~kg}(0.4 \%)$ observed in this study. Our findings and the evidence from corroborative research $(6,11)$ demonstrate the reproducibility of 1RM PC performance in relatively inexperienced athletes. In light of this practitioners should look for a change in 1RM PC performance of $>3.77 \mathrm{~kg}(6.04 \%)$ to be considered a meaningful change in inexperienced male youth soccer players.

The results from this study provide isometric force-time characteristics and 1RM PC data in male youth soccer players where research providing this data is limited. It should be acknowledged that a relatively low sample size was used in the present study and it is therefore recommended more data is required providing isometric force time-characteristics and 1RM PC data so normative data can be established in this population.

\section{PRACTICAL APPLICATIONS}

The results of this study demonstrate that 1RM PC, IMTP PF and time-specific force values and are highly reliable within-session and between-sessions in male youth soccer players. Furthermore, no significant differences in PC and IMTP kinetics were observed between sessions suggesting there was no learning effect. Strength and conditioning coaches and practitioners should consider changes of $>6.04 \%$ in $1 \mathrm{RM}$ PC meaningful in male youth soccer players. Furthermore, the highest reliability and lowest measurement errors of all IMTP kinetics were observed in PF and force 250 and therefore may be more appropriate for monitoring sensitive changes in neuromuscular performance. Consequently, changes of $>7.23 \%$ in force 250 and $>8.50 \%$ in $\mathrm{PF}$ should be considered a true improvement in neuromuscular performance from a training intervention in male youth soccer players. 
Decrements in the IMTP kinetics greater than aforementioned values could possibly be used as an indicator of neuromuscular fatigue and preparedness for training or competition.

\section{ACKNOWLEDGMENTS}

The authors would like to thank the individuals who participated in this investigation. No grant funding was received to support this research and the authors have no conflict of interest.

\section{REFERENCES}

1. Baker D. The effects of an in-season of concurrent training on the maintenance of maximal strength and power in professional and college-aged rugby league football players. The Journal of Strength \& Conditioning Research 15: 172-177, 2001.

2. Baumgartner TA and Chung $\mathrm{H}$. Confidence limits for intraclass reliability coefficients. Meas Phys Educ Exerc Sci 5: 179-188, 2001.

3. Beattie K, Carson BP, Lyons M, and Kenny IC. The Effect of Maximal-\& Explosive-Strength Training on Performance Indicators in Cyclists. International journal of sports physiology and performance: Published Ahead of Print, 2016.

4. Beckham G, Mizuguchi S, Carter C, Sato K, Ramsey M, Lamont H, Hornsby G, Haff G, and Stone M. Relationships of isometric mid-thigh pull variables to weightlifting performance. $J$ Sports Med Phys Fitness 53: 573-581, 2013.

5. Comfort P, Jones PA, McMahon JJ, and Newton R. Effect of Knee and Trunk Angle on Kinetic Variables During the Isometric Mid-Thigh Pull: Test-Retest Reliability. Int I Sports Physiol and Perform 10: 58-63, 2015.

6. Comfort $P$ and McMahon JJ. Reliability of maximal back squat and power clean performances in inexperienced athletes. The Journal of Strength \& Conditioning Research 29: 3089-3096, 2015.

7. De Witt JK, English KL, Crowell JB, Kalogera KL, Guilliams ME, Nieschwitz BE, Hanson AM, and Ploutz-Snyder LL. Isometric Mid-Thigh Pull Reliability and Relationship to Deadlift 1RM. The Journal of Strength \& Conditioning Research: Published Ahead of Print, 2016.

8. Dos' Santos T, Jones PA, Kelly J, McMahon JJ, Comfort P, and Thomas C. Effect of Sampling Frequency on Isometric Mid-Thigh Pull Kinetics. Int J Sports Physiol and Perform 11: 255-260, 2016.

9. Dos'Santos T, Thomas C, Jones AP, and Comfort P. Mechanical determinants of faster change of direction speed performance in male athletes. The Journal of Strength \& Conditioning Research: Published Ahead of Print, 2016.

10. Dos'Santos T, Thomas $C$, Jones PA, and Comfort P. Assessing muscle strength asymmetry via a unilateral stance isometric mid-thigh pull. International journal of sports physiology and performance: Published Ahead of Print, 2016.

11. Faigenbaum AD, McFarland JE, Herman R, Naclerio F, Ratamess NA, Kang J, and Myer GD. Reliability of the one repetition-maximum power clean test in adolescent athletes. Journal of 
strength and conditioning research/National Strength \& Conditioning Association 26: 432, 2012.

12. Faul F, Erdfelder E, Buchner A, and Lang A-G. Statistical power analyses using G* Power 3.1: Tests for correlation and regression analyses. Behav Res Methods 41: 1149-1160, 2009.

13. Gabbett TJ. Changes in physiological and anthropometric characteristics of rugby league players during a competitive season. The Journal of Strength \& Conditioning Research 19: 400-408, 2005.

14. Garhammer J. A Review of Power Output Studies of Olympic and Powerlifting: Methodology, Performance Prediction, and Evaluation Tests. The Journal of Strength \& Conditioning Research 7: 76-89, 1993.

15. Gescheit DT, Cormack SJ, Reid M, and Duffield R. Consecutive Days of Prolonged Tennis Match Play: Performance, Physical, and Perceptual Responses in Trained Players. International Journal of Sports Physiology \& Performance 10, 2015.

16. Haff GG, Carlock JM, Hartman MJ, Kilgore JL, Kawamori N, Jackson JR, Morris RT, Sands WA, and Stone MH. Force--Time Curve Characteristics of Dynamic and Isometric Muscle Actions of Elite Women Olympic Weightlifters. J Strength Cond Res 19: 741-748, 2005.

17. Haff GG and Nimphius S. Training principles for power. Strength Cond J 34: 2-12, 2012

18. Haff GG, Ruben RP, Lider J, Twine C, and Cormie P. A comparison of methods for determining the rate of force development during isometric midthigh clean pulls. The Journal of Strength \& Conditioning Research 29: 386-395, 2015.

19. Haff GG, Stone M, O'Bryant HS, Harman E, Dinan C, Johnson R, and Han K-H. Force-time dependent characteristics of dynamic and isometric muscle actions. J Strength Cond Res 11: 269-272, 1997.

20. Haff GG and Triplett NT. Essentials of Strength Training and Conditioning 4th Edition. Human kinetics, 2015.

21. Hopkins WG. Reliability from consecutive pairs of trials (Excel spreadsheet). A new view of statistics 2016, 2000.

22. Hopkins WG. A scale of magnitudes for effect statistics. A new view of statistics, 2002.

23. K. Beckham G, S. Lamont H, Sato K, W. Ramsey M, and H. Stone M. Isometric strength of powerlifters in key positions of the conventional deadlift. Journal of Trainology 1: 32-35, 2012.

24. Kraska JM, Ramsey MW, Haff GG, Fethke N, Sands WA, Stone ME, and Stone MH. Relationship between strength characteristics and unweighted and weighted vertical jump height. Int J Sports Physiol Perform 4: 461-473, 2009.

25. Kropmans TJB, Dijkstra PU, Stegenga B, Stewart R, and De Bont LGM. Smallest detectable difference in outcome variables related to painful restriction of the temporomandibular joint. Journal of dental research 78: 784-789, 1999.

26. Leary BK, Statler J, Hopkins B, Fitzwater R, Kesling T, Lyon J, Phillips B, Bryner RW, Cormie P, and Haff GG. The relationship between isometric force-time curve characteristics and club head speed in recreational golfers. J Strength Cond Res 26: 2685-2697, 2012.

27. McGuigan MR, Cormack SJ, and Gill ND. Strength and Power Profiling of Athletes: Selecting Tests and How to Use the Information for Program Design. Strength \& Conditioning Journal 35: 7-14, 2013.

28. McGuigan MR, Newton MJ, Winchester JB, and Nelson AG. Relationship between isometric and dynamic strength in recreationally trained men. J Strength Cond Res 24: 2570-2573, 2010.

29. McGuigan MR, Winchester JB, and Erickson T. The importance of isometric maximum strength in college wrestlers. J Sports Sci Med 5: 108-113, 2006.

30. Newton RU and Kraemer WJ. Developing Explosive Muscular Power: Implications for a Mixed Methods Training Strategy. Strength Cond J 16: 20-31, 1994. 
31. Sheppard JM, Nimphius S, Haff GG, Tran TT, Spiteri T, Brooks H, Slater G, and Newton RU. Development of a Comprehensive Performance-Testing Protocol for Competitive Surfers. Int J Sports Physiol and Perform 8: 490-495, 2013.

32. Stone MH, Sanborn K, O'Bryant HS, Hartman M, Stone ME, Proulx C, Ward B, and Hruby J. Maximum strength-power-performance relationships in collegiate throwers. J Strength Cond Res 17: 739-745, 2003.

33. Stone MH, Sands WA, Carlock JON, Callan SAM, Dickie DES, Daigle K, Cotton J, Smith SL, and Hartman $M$. The importance of isometric maximum strength and peak rate-of-force development in sprint cycling. J Strength Cond Res 18: 878-884, 2004.

34. Suchomel TJ, Comfort $\mathrm{P}$, and Stone $\mathrm{MH}$. Weightlifting pulling derivatives: Rationale for implementation and application. Sports Medicine 45: 823-839, 2015.

35. Taylor K-L, Hopkins WG, Chapman DW, and Cronin JB. The Influence of Training Phase on Error of Measurement in Jump Performance. International Journal of Sports Physiology \& Performance 11: 235-239, 2016.

36. Thomas $\mathrm{C}$, Comfort $\mathrm{P}, \mathrm{Chiang} \mathrm{C}-\mathrm{Y}$, and $\mathrm{A}$. Jones $\mathrm{P}$. Relationship between isometric mid-thigh pull variables and sprint and change of direction performance in collegiate athletes. Journal of Trainology 4: 6-10, 2015.

37. Thomas C, Jones PA, and Comfort P. Reliability of the Dynamic Strength Index in Collegiate Athletes. Int J Sports Physiol and Perform 10: 542 -545, 2015.

38. Thomas JR, Nelson, JK., Silverman SJ. Research Methods in Physical Activity. Champaign, IL: Human Kinetics, 2005.

39. Turner A, Walker S, Stembridge M, Coneyworth P, Reed G, Birdsey L, Barter P, and Moody J. A testing battery for the assessment of fitness in soccer players. Strength \& Conditioning Journal 33: 29-39, 2011.

40. Turner AN and Stewart PF. Strength and conditioning for soccer players. Strength \& Conditioning Journal 36: 1-13, 2014.

41. West DJ, Owen NJ, Jones MR, Bracken RM, Cook CJ, Cunningham DJ, Shearer DA, Finn CV, Newton RU, and Crewther BT. Relationships between force time characteristics of the isometric midthigh pull and dynamic performance in professional rugby league players. $J$ Strength Cond Res 25: 3070-3075, 2011.

42. Weyand PG, Sternlight DB, Bellizzi MJ, and Wright S. Faster top running speeds are achieved with greater ground forces not more rapid leg movements. Journal of applied physiology 89: 1991-1999, 2000. 
Table 1. Within-session reliability of IMTP kinetics $(n=13)$

\begin{tabular}{|c|c|c|c|c|c|c|c|c|c|c|}
\hline \multirow[b]{2}{*}{ Variable } & \multicolumn{5}{|c|}{ Session 1} & \multicolumn{5}{|c|}{ Session 2} \\
\hline & Mean & SD & $\begin{array}{c}\text { ICC } \\
(95 \% \mathrm{CI}) \\
\end{array}$ & $\begin{array}{c}\text { CV (\%) } \\
(95 \% \text { CI) }\end{array}$ & $\begin{array}{c}\text { TE } \\
(95 \% \text { CI }) \\
\end{array}$ & Mean & SD & $\begin{array}{c}\text { ICC } \\
(95 \% \text { CI }) \\
\end{array}$ & $\begin{array}{c}\text { CV (\%) } \\
(95 \% \text { CI) }\end{array}$ & $\begin{array}{c}\text { TE } \\
(95 \% \text { CI }) \\
\end{array}$ \\
\hline Force at $30 \mathrm{~ms}(\mathrm{~N})$ & 925.92 & 131.01 & $\begin{array}{c}0.88 \\
(0.69-0.96)\end{array}$ & $\begin{array}{c}7.48 \\
(5.71-11.49)\end{array}$ & $\begin{array}{c}69.26 \\
(52.90-106.36)\end{array}$ & 897.62 & 120.43 & $\begin{array}{c}0.87 \\
(0.69-0.96)\end{array}$ & $\begin{array}{c}9.55 \\
(6.53-13.18)\end{array}$ & $\begin{array}{c}85.72 \\
(58.60-118.27)\end{array}$ \\
\hline Force at $50 \mathrm{~ms}(\mathrm{~N})$ & 1040.65 & 166.15 & $\begin{array}{c}0.85 \\
(0.60-0.95)\end{array}$ & $\begin{array}{c}9.00 \\
(6.86-13.88)\end{array}$ & $\begin{array}{c}93.66 \\
(71.44-144.41)\end{array}$ & 1007.51 & 147.40 & $\begin{array}{c}0.86 \\
(0.64-0.95)\end{array}$ & $\begin{array}{c}9.70 \\
(7.41-15.01)\end{array}$ & $\begin{array}{c}97.73 \\
(74.62-151.22)\end{array}$ \\
\hline Force at $90 \mathrm{~ms}(\mathrm{~N})$ & 1154.32 & 182.58 & $\begin{array}{c}0.85 \\
(0.63-0.95)\end{array}$ & $\begin{array}{c}9.85 \\
(7.51-15.22)\end{array}$ & $\begin{array}{c}113.70 \\
(86.67-175.71)\end{array}$ & 1150.25 & 159.26 & $\begin{array}{c}0.88 \\
(0.70-0.96)\end{array}$ & $\begin{array}{c}8.35 \\
(6.37-12.86)\end{array}$ & $\begin{array}{c}96.05 \\
(73.33-147.88)\end{array}$ \\
\hline Force at $100 \mathrm{~ms}(\mathrm{~N})$ & 1173.46 & 180.25 & $\begin{array}{c}0.84 \\
(0.61-0.95)\end{array}$ & $\begin{array}{c}10.00 \\
(7.62-15.46)\end{array}$ & $\begin{array}{c}117.35 \\
(89.44-181.43)\end{array}$ & 1179.87 & 169.60 & $\begin{array}{c}0.88 \\
(0.71-0.96)\end{array}$ & $\begin{array}{c}8.15 \\
(6.22-12.53)\end{array}$ & $\begin{array}{c}96.10 \\
(73.38-147.89)\end{array}$ \\
\hline Force at $150 \mathrm{~ms}(\mathrm{~N})$ & 1381.37 & 229.13 & $\begin{array}{c}0.90 \\
(0.75-0.97)\end{array}$ & $\begin{array}{c}8.24 \\
(6.29-12.69)\end{array}$ & $\begin{array}{c}113.82 \\
(86.93-175.26)\end{array}$ & 1426.00 & 213.60 & $\begin{array}{c}0.88 \\
(0.70-0.96)\end{array}$ & $\begin{array}{c}8.46 \\
(6.46-13.03)\end{array}$ & $\begin{array}{c}120.68 \\
(92.12-185.86)\end{array}$ \\
\hline Force at $200 \mathrm{~ms}(\mathrm{~N})$ & 1614.00 & 224.37 & $\begin{array}{c}0.90 \\
(0.75-0.97)\end{array}$ & $\begin{array}{c}6.58 \\
(5.03-10.09)\end{array}$ & $\begin{array}{c}106.20 \\
(81.23-162.81)\end{array}$ & 1654.42 & 212.04 & $\begin{array}{c}0.89 \\
(0.72-0.96)\end{array}$ & $\begin{array}{c}7.32 \\
(5.59-11.24)\end{array}$ & $\begin{array}{c}121.05 \\
(92.51-185.90)\end{array}$ \\
\hline Force at $250 \mathrm{~ms}(\mathrm{~N})$ & 1722.76 & 222.13 & $\begin{array}{c}0.91 \\
(0.77-0.97)\end{array}$ & $\begin{array}{c}5.69 \\
(4.36-8.71)\end{array}$ & $\begin{array}{c}98.03 \\
(75.13-150.10)\end{array}$ & 1744.13 & 230.05 & $\begin{array}{c}0.94 \\
(0.84-0.98)\end{array}$ & $\begin{array}{c}5.74 \\
(4.39-8.78)\end{array}$ & $\begin{array}{c}100.10 \\
(76.64-153.15)\end{array}$ \\
\hline Peak force $(\mathrm{N})$ & 2230.18 & 347.16 & $\begin{array}{c}0.98 \\
(0.94-0.99) \\
\end{array}$ & $\begin{array}{c}4.05 \\
(3.10-6.17) \\
\end{array}$ & $\begin{array}{c}90.32 \\
(69.22-137.49) \\
\end{array}$ & 2240.58 & 337.94 & $\begin{array}{c}0.97 \\
(0.93-0.99) \\
\end{array}$ & $\begin{array}{c}4.26 \\
(3.27-6.49) \\
\end{array}$ & $\begin{array}{c}95.46 \\
(73.21-145.52) \\
\end{array}$ \\
\hline
\end{tabular}

Key: ICC = Intraclass Correlation Coefficient; CV = Coefficient of Variation; TE = Typical Error of Measurement; CI = Confidence Interval 
Table 2. Between-session reliability of IMTP kinetics $(n=13)$

\begin{tabular}{|c|c|c|c|c|c|c|c|c|c|c|c|c|}
\hline \multirow{2}{*}{ Variable } & \multicolumn{2}{|c|}{ Session 1} & \multicolumn{2}{|c|}{ Session 2} & \multirow{2}{*}{$\mathbf{p}$} & \multirow{2}{*}{$\mathbf{E S}$} & \multirow{2}{*}{$\begin{array}{c}\text { ICC } \\
(95 \% \mathrm{CI})\end{array}$} & \multirow{2}{*}{$\begin{array}{c}\text { CV (\%) } \\
(95 \% \text { CI) }\end{array}$} & \multirow{2}{*}{$\begin{array}{c}\text { TE } \\
(95 \% \mathrm{CI})\end{array}$} & \multirow{2}{*}{ SEM } & \multirow{2}{*}{$\begin{array}{l}\text { SDD } \\
(\%)\end{array}$} & \multirow{2}{*}{ Power } \\
\hline & Mean & SD & Mean & SD & & & & & & & & \\
\hline Force at $30 \mathrm{~ms}(\mathrm{~N})$ & 925.92 & 131.01 & 897.62 & 120.43 & 0.27 & 0.22 & $\begin{array}{c}0.86 \\
(0.55-0.96)\end{array}$ & $\begin{array}{c}7.87 \\
(5.58-13.32)\end{array}$ & $\begin{array}{c}71.76 \\
(50.90-121.45)\end{array}$ & 47.08 & $\begin{array}{l}130.50 \\
(14.31)\end{array}$ & 0.18 \\
\hline
\end{tabular}




\begin{tabular}{|c|c|c|c|c|c|c|c|c|c|c|c|c|}
\hline Force at $50 \mathrm{~ms}(\mathrm{~N})$ & 1040.65 & 166.15 & 1007.51 & 147.40 & 0.26 & 0.21 & $\begin{array}{c}0.88 \\
(0.64-0.96)\end{array}$ & $\begin{array}{c}7.86 \\
(5.58-13.31)\end{array}$ & $\begin{array}{c}80.53 \\
(57.12-136.30)\end{array}$ & 54.41 & $\begin{array}{l}150.80 \\
(14.73)\end{array}$ & 0.18 \\
\hline \multirow[t]{2}{*}{ Force at $90 \mathrm{~ms}(\mathrm{~N})$} & \multirow[t]{2}{*}{1154.32} & \multirow[t]{2}{*}{182.58} & 1179.87 & 169.60 & 0.83 & -0.04 & $\begin{array}{c}0.91 \\
0.97)\end{array}$ & 6.75 & 77.80 & 51.40 & 142.26 & \\
\hline & & & \multicolumn{9}{|c|}{ Table 3. Between-session reliability of maximal power clean $(\mathbf{n}=\mathbf{( 1 0}=\mathbf{1 0}) \quad(55.27-131.23)$} & 0.12 \\
\hline \multirow{2}{*}{$\begin{array}{c}\text { Force at } 100 \mathrm{~ms}(\mathrm{~N}) \\
\text { Variable }\end{array}$} & \multicolumn{2}{|c|}{117 Sagsion 1180.25} & \multicolumn{2}{|c|}{$1179 s e 3 s i o n$ D69.60 } & \multirow{2}{*}{$\underset{\mathbf{p}}{0.83}$} & \multirow{2}{*}{$\stackrel{-0.04}{\mathbf{E S}}$} & \multirow{2}{*}{ (95\% ICI) } & \multirow{2}{*}{$\begin{array}{c}\left(\begin{array}{c}0.10 \\
(80-1 \\
(95 \%) \\
7.67\end{array}\right) \\
7.67\end{array}$} & \multirow{2}{*}{$\begin{array}{c}\left(56477^{4-1}=3408\right) \\
107.62) \\
107.62\end{array}$} & \multirow{2}{*}{$\begin{array}{l}55.20 \\
\text { SEM }\end{array}$} & \multirow{2}{*}{$\begin{array}{c}145.53 \\
\text { (PDP) } \\
\text { (\%) } \\
203.63\end{array}$} & \multirow{2}{*}{ Poover } \\
\hline & Mean & SD & Mean & SD & & & & & & & & \\
\hline Force ${ }_{1 \mathrm{R}} 15 \mathrm{PC}^{\mathrm{ms}}(\mathrm{N})$ & 1628257 & 229593 & 1626500 & $2 \$ 3800$ & 0.28 & -0.00 & $\begin{array}{c}0.96 \\
(8: 84-8.87)\end{array}$ & $(52.41-5.987)$ & $(76.336 .1383 .934)$ & 73.46 & $\begin{array}{r}20393 \\
(14.041) \\
(6.04)\end{array}$ & 8.96 \\
\hline \multicolumn{12}{|c|}{ 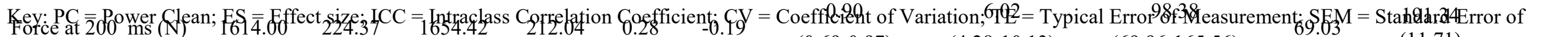 } & $\begin{array}{l}\text { of } \\
0.15\end{array}$ \\
\hline Force at $250 \mathrm{~ms}(\mathrm{~N})$ & 1722.76 & 222.13 & 1744.13 & 230.05 & 0.39 & -0.09 & $\begin{array}{c}0.96 \\
(0.88-0.99)\end{array}$ & $\begin{array}{c}3.76 \\
(2.68-6.28)\end{array}$ & $\begin{array}{c}65.12 \\
(46.45-108.80)\end{array}$ & 45.23 & $\begin{array}{l}125.36 \\
(7.23)\end{array}$ & 0.10 \\
\hline Peak force $(\mathrm{N})$ & 2230.18 & 347.16 & 2240.58 & 337.94 & 0.78 & -0.03 & $\begin{array}{c}0.96 \\
(0.88-0.99)\end{array}$ & $\begin{array}{c}4.61 \\
(3.28-7.72)\end{array}$ & $\begin{array}{c}103.04 \\
(73.42-172.63)\end{array}$ & 68.52 & $\begin{array}{l}189.92 \\
(8.50)\end{array}$ & 0.06 \\
\hline
\end{tabular}

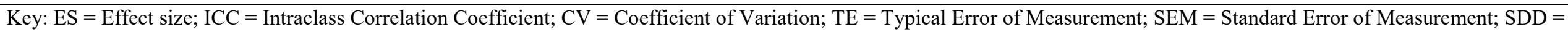
Smallest Detectable difference; $\mathrm{CI}=$ Confidence Interval 
Measurement; SDD = Smallest Detectable difference; $\mathrm{CI}=$ Confidence Interval 